\title{
Activity outside the home, environmental barriers, and healthy aging for community-dwelling elderly individuals in China
}

\author{
Yuhong Niu ${ }^{1, \S}$, Na Li ${ }^{1, \S}$, Chunlin Jin ${ }^{1}$, Duo Chen ${ }^{1}$, Yitong Yang ${ }^{2}$, Hansheng Ding ${ }^{1, *}$ \\ ${ }^{1}$ Shanghai Health Development Research Center, Shanghai, China; \\ ${ }^{2}$ University of Finance and Economics, Shanghai, China.
}

\begin{abstract}
Summary Elderly individuals benefit from frequently engaging in activities outside the home because such activities sustain the overall health and functioning of an aging body. However, environmental barriers can limit participation in activities outside the home by elderly individuals. The current study examined the factors that influence the frequency with which elderly individuals living in China engage in activity outside the home. Data were collected from 2,402 elderly individuals residing in the Jiangning district of Shanghai, China in 2015. Face-to-face interviews were conducted based on a questionnaire, and multiple regression analysis was used to measure influencing factors. Results revealed that elderly respondents with a better self-reported health status $(p=0.2499)$ engaged in activities outside the home more frequently. In addition, elderly respondents residing on higher floors of multi-floor residential buildings $(p<0.001)$ were less likely to participate in activities outside of the home. This effect was virtually eliminated, however, when the residence in question was equipped with an elevator $(p<0.001)$.
\end{abstract}

Keywords: Floor of residence, multi-floor residential building, activities outside the home, elevator, elderly individuals

Activity outside the home plays an important role in maintaining health among the elderly. Activity outside the home refers to activities performed in daily life and includes activities related to social networking, work, and transportation (1-3). Regular outings from a limited "living area" (i.e. an area where a person spends large amounts of time engaged in everyday activity) facilitates participation in meaningful activities within a society (4). These social activities may help the elderly ameliorate feelings of loneliness, build social networks, and satisfy social needs. In addition to the social aspects, elderly individuals engage in the most intense levels of physical activity outside of the home (5). Previous studies have suggested that going outside less frequently is associated with poorer overall health and mental problems in the elderly. Therefore, the elderly benefit from engaging in activities outside the home with a certain frequency since such activities sustain overall health and functioning in comparison to individuals who do not engage in activities

\footnotetext{
${ }^{\S}$ These authors contributed equally to this work.

*Address correspondence to:

Dr. Hansheng Ding, Development Research Center, Shanghai

Health Development Research Center, Beijing (W) Road

No.1477, Jingan District, Shanghai 200040, China.

E-mail: dinghansheng@hotmail.com
}

outside the home (6-8)

In 2007, the World Health Organization collected basic information on elderly people in 33 nations and then published Global age-friendly cities: A guide (9). This guide suggests that multi-floor residential buildings be equipped with an elevator if residents are elderly individuals. An age-friendly city has buildings that are more accessible to meet the varying needs of elderly people. Accordingly, elderly individuals need to reside on lower floors of residential buildings or have access to an elevator in a multi-floor residential building to remain able to engage in activities outside the home. Moreover, the 2015 World Report on Aging and Health outlines a framework for action to foster Healthy Aging built around the new concept of functional ability (10). The report indicated that architectural obstacles need to be reduced in order to facilitate activity by the elderly and it also revealed that varying levels of physical functioning and mental ability may limit activity by the elderly. Therefore, architectural plans need to feature ramps, handrails, elevators, and appropriated signage to facilitate use by the elderly, regardless of their level of activity.

Environmental barriers are associated with unsatisfactory living conditions or inadequate infrastructure. The elderly are predicted to have 
significantly lower scores for activities of daily living (ADL) and instrumental activities of daily living (IADL) if environmental barriers restrict their ability to engage in activities outside the home (11). This finding is substantiated by correlations between environmental barriers and restricted ability to engage in activities outside the home. In addition, many studies have provided evidence of an association between depressive mood and engaging in activities outside the home less frequently due to environmental barriers $(5,7,8)$. A European study on how environmental barriers influence activities outside the home found that an environment of poor quality and poor street connectivity led to elderly individuals being unwilling go outside (12). In contrast, a Tokyo study found that green spaces near the residence of elderly individuals encourage their desire to engage in activities outside the home and may decrease their risk of mortality (11).

Unquestionably, Chinese elderly are faced with the environmental barriers mentioned earlier. However, there is one particular environmental barrier that many
Chinese elderly are likely to face but that Western elderly may not encounter. This particular environmental barrier is living in an apartment building that is not equipped with an elevator because of the age of many residential buildings in China. Descending stairs may hamper elderly individuals from engaging in activities outside the home, and thus eventually lead to inactivity. This inactivity, in turn, results in a decline in health and functioning. For this population, environmental pressure may decrease the desire to engage in activities outside the home.

According to China's Design Code for Residential Buildings promulgated in 1987, a building with more than 7 floors must be equipped with an elevator. In 2016, the elderly population ( $\geq$ the age of 60 ) in Shanghai totaled 4.58 million (13). Recent statistics indicated that 1.8 million elderly people resided in old buildings in Shanghai in 2013 (14). Old buildings referred to a three- (or four) story house or an older style building with fewer than seven floors. None of these old buildings were equipped with an elevator.

In order to investigate whether the floor of residence

Table 1. Baseline characteristics of elderly individuals who had to descend stairs or who lived on the ground floor/had access to an elevator

\begin{tabular}{|c|c|c|c|}
\hline Items & $\begin{array}{l}\text { Descended stairs to engage in exercise } \\
\text { outside the home, } \mathrm{N}(\%)\end{array}$ & $\begin{array}{l}\text { Live on the ground floor or used an elevator to } \\
\text { engage in exercise outside the home, } \mathrm{N}(\%)\end{array}$ & $p$ value \\
\hline Gender & & & 0.9762 \\
\hline Male & $668(58.09)$ & $482(41.91)$ & \\
\hline Female & $728(58.15)$ & $524(41.85)$ & \\
\hline Age & $71.24 \pm 7.34$ & $70.57 \pm 7.01$ & 0.0441 \\
\hline ADL & $19.62 \pm 0.84$ & $19.74 \pm 0.88$ & $<0.0001$ \\
\hline IADL & $7.67 \pm 0.94$ & $7.72 \pm 0.86$ & 0.1754 \\
\hline Self-reported health* & & & 0.2499 \\
\hline Unhealthy & $612(59.48)$ & $417(40.52)$ & \\
\hline Healthy & $781(57.13)$ & $586(42.87)$ & \\
\hline Floor of residence & & & $<0.0001$ \\
\hline Ground floor & $0(0)$ & $509(100)$ & \\
\hline Second floor & $471(97.52)$ & $12(2.48)$ & \\
\hline Third floor & $310(95.98)$ & $13(4.02)$ & \\
\hline Fourth floor & $232(91.7)$ & $21(8.3)$ & \\
\hline Fifth floor & $182(83.49)$ & $36(16.51)$ & \\
\hline Sixth floor & $169(81.25)$ & $39(18.75)$ & \\
\hline Seventh floor & $32(43.84)$ & $41(56.16)$ & \\
\hline$>$ Seventh floor & $0(0)$ & $335(100)$ & \\
\hline Activities & & & $<0.0001$ \\
\hline Inside only & $237(69.1)$ & $106(30.9)$ & \\
\hline Outside the home & $1,159(56.29)$ & $900(43.71)$ & \\
\hline
\end{tabular}

ADL refers to routine activities in daily life that people are capable of performing, without assistance. These necessary functions include eating, bathing, dressing, and toileting; IADL refers to instrumental activities of daily living, including light housework, food preparation, shopping, and managing one's finances. ${ }^{*} 6$ of 2,402 respondents did not respond to the question about self-reported health on the questionnaire.

Table 2. Factors influencing the desire of respondents to engage in activities outside the home

\begin{tabular}{|c|c|c|c|}
\hline Effects & Point Estimate & 95\% Wald Confidence Interval & $p$ value \\
\hline Age & 0.913 & $0.896-0.930$ & $<0.0001$ \\
\hline Gender (Female vs. Male) & 1.139 & $0.875-1.483$ & 0.3323 \\
\hline Self-reported health status (Healthy $v s$. Unhealthy) & 3.048 & $2.304-4.034$ & $<0.0001$ \\
\hline $\mathrm{ADL}$ & 1.068 & $0.936-1.219$ & 0.3296 \\
\hline IADL & 1.480 & $1.303-1.682$ & $<0.0001$ \\
\hline Elevator (Yes vs. No) & 2.051 & $1.519-2.768$ & $<0.0001$ \\
\hline Floor of residence & 0.968 & $0.939-0.998$ & 0.0342 \\
\hline
\end{tabular}

ADL refers to routine activities in daily life that people are capable of performing, without assistance. These necessary functions include eating, bathing, dressing, and toileting; IADL refers to instrumental activities of daily living, including light housework, food preparation, shopping, and managing one's finances. ${ }^{*} 6$ of 2,402 respondents did not respond to the question about self-reported health on the questionnaire. 
influences the desire of community-dwelling elderly to engage in activities outside the home, 2,402 active individuals age 60 or older residing in the Jiangning district of Shanghai, China were surveyed. Face-toface interviews were conducted in 2015 based on a questionnaire. Respondents were divided into two groups: respondents who had to descend stairs to go outside and respondents who lived on the ground floor or who did not need to descend stairs as a result of access to an elevator. Demographic characteristics including age, gender, and self-reported health status and physical status including scores for both ADL and IADL were obtained. Multiple regression analysis was used to identify the factors influencing the desire of respondents to engage in activities outside the home.

As shown in Tables 1 and 2, the results yielded three interesting findings. First, elderly respondents with a better self-reported health status engaged in activities outside the home more frequently. Second, the floor on which a respondent resided was associated with the frequency with which the respondent engaged in activities outside the home. Further, the current study found that residing on a higher floor of a building resulted in less desire to engage in activities outside the home. Interestingly, respondents residing in an apartment building equipped with an elevator retained the desire to go outside and remain active, and these individuals were less influenced by the floor on which they resided. The results indicate that an elevator is extremely important within this context, enabling improvement of a less than ideal situation.

Activity outside the home is quite important to successful aging. Environmental barriers predict a significant decline in activity outside the home. In the current study, descending stairs represented a substantial environmental barrier to engaging in activities outside the home. Unfortunately, most of the old apartment buildings in China lack an elevator, so residents must descend stairs to go outside. However, an elevator can eliminate that problem. In light of this information, multifloor residential buildings with elderly residents should be equipped with an elevator. Moreover, results of the selfreported health status indicated that elderly individuals with a better self-reported health status engaged in activities outside the home more frequently. This suggests that relatives, and society at large, should encourage those individuals to engage in activities outside of the home.

\section{Acknowledgements}

The study was supported by grants from the National Natural Science Foundation of China (grant no. 71073104/ G0308), the China Medical Board's Program for Collaboration in Healthcare Research and Policymaking (CMB-CP 14-190), and Projects in the Three-year Action Plan of the Shanghai Health and Family Planning Commission (grant no. 43). The sponsor had no role in the design or conduct of the study; collection, management, analysis, or interpretation of the data; or the preparation, review, or approval of the manuscript.

\section{References}

1. Simonsick EM, Guralnik JM, Volpato S, Balfour J, Fried LP. Just get out the door! Importance of walking outside the home for maintaining mobility: Findings from the Women's Health and Aging Study. J Am Geriatr Soc. 2005; 53:198203.

2. Brach JS, Simonsick EM, Kritchevsky S, Yaffe K, Newman AB; Health, Aging and Body Composition Study Research Group. The association between physical function and lifestyle activity and exercise in the health aging and body composition study. J Am Geriatr Soc. 2004: 52:502509.

3. Varma VR, Tan EJ, Wang T, Xue QL, Fried LP, Seplaki CL, King AC, Seeman TE, Rebok GW, Carlson MC. Lowintensity walking activity is associated with better health. $\mathrm{J}$ Appl Gerontol. 2014: 33:870-887.

4. Portegijs E, Tsai LT, Rantanen T, Rantakokko M. Moving through life-space areas and objectively measured physical activity of older people. PLoS One. 2015; 10:e0135308.

5. Kerr J, Sallis JF, Saelens BE, Cain KL, Conway TL, Frank LD, King AC. Outdoor physical activity and self-rated health in older adults living in two regions of the U.S. Int J Behav Nutr Phys Act. 2012; 9:89.

6. Jacobs JM, Cohen A, Hammerman-Rozenberg R, Azoulay D, Maaravi Y, Stessman J. Going outdoors daily predicts long-term functional and health benefits among ambulatory older people. J Aging Health. 2008; 20:259-272.

7. Shimada H, Ishizaki T, Kato M, Morimoto A, Tamate A, Uchiyama Y, Yasumura S. How often and how far do frail elderly people need to go outdoors to maintain functional capacity? Arch Gerontol Geriatr. 2010; 50:140-146.

8. Fujita K, Fujiwara Y, Chaves PH, Motohashi Y, Shinkai S. Frequency of going outdoors as a good predictors for incident disability of physical function as well as disability recovery in community-dwelling older adults in rural Japan. J Epidemiol. 2006; 16:261-270.

9. WHO. Aging and Life Course, Global age-friendly cities: A guide. http://www.who.int/ageing/age friendly_cities_ guide/en/ (accessed October 5, 2017).

10. WHO, Aging and Life Course, World report on ageing and health 2015. http://www.who.int/ageing/events/worldreport-2015-launch/en/(accessed September 30, 2017).

11. Rantakokko M, Törmäkangas T, Rantanen T, Haak M, Iwarsson S. Environmental barriers, person-environment fit and mortality among community-dwelling very old people. BMC Public Health. 2013; 13:783.

12. Golant SM. Handbook of Aging and the Social Sciences, United States, 2011; pp. 207-212

13. Wu ZD. People's daily online. data show: By the end of December 2016, the elderly will account for over $31 \%$ of the population of Shanghai. http://www.cssn.cn/shx/ shx_sjzx/201703/t20170329_3470307.shtml (accessed September 29, 2017) (in Chinese)

14. The evening news, Elderly people despair without access to an elevator to go outside and cool off. http://newspaper. jfdaily.com/xwwb/html/2013-08/05/content_1071120.htm (accessed September 5, 2017) (in Chinese)

(Received September 26, 2017; Revised October 16, 2017; Accepted October 18, 2017) 